Панькин Павел Владимирович

старший преподаватель кафедры экономики, экономического анализа и менеджмента Елецкого государственного университета имени И.А. Бунина

\section{ВЛИЯНИЕ ТРУДОВОЙ МИГРАЦИИ НА РЫНОК ТРУДА ЛИПЕЦКОЙ ОБЛАСТИ И ЦЕЛЕВЫЕ ОРИЕНТИРЫ ЕГО РАЗВИТИЯ}

Аннотация:

В статье рассмотрены значимость трудовой миграции и ее влияние на рынок труда Липецкой области на основе корреляционного и кластерного анализа. Выявлено, что количество прибывающих мигрантов оказывает влияние на такие социальноэкономические показатели, как нагрузка на тысячу человек населения трудоспособного возраста, результативность миграционных связей, эффективность миграции, напряженность на рынке труда, миграционная нагрузка на рынок труда. Проведена дифференциация муниципальных образований Липецкой области по выделенным показателям, характеризующим миграцию в регионе, которая позволила определить группы с высоким и низким влиянием миграционных процессов на рынок труда. Сформулированы целевые ориентиры развития регионального рынка труда с учетом факторов влияния на миграцию, обеспечивающих его сбалансированность и дальнейшее развитие. В основе целевых ориентиров развития лежат унификация статистического учета миграции, повышение уровня социально-экономических условий и совершенствование нормативно-правовой базы.

\section{Ключевые слова:}

миграция, трудовая миграция, рынок труда, рабочая сила, миграционные процессы, корреляционный анализ, кластерный анализ, целевые ориентиры развития, Липецкая область.
Pankin Pavel Vladimirovich

Senior Lecturer, Department of Economy, Economic Analysis and Management, Yelets State University

\section{THE IMPACT OF LABOR MIGRATION ON THE LABOR MARKET IN THE LIPETSK REGION AND ITS DEVELOPMENT TARGETS}

\section{Summary:}

The study discusses the significance of labor migration and its impact on the labor market of the Lipetsk region based on correlation and cluster analysis. The paper reveals that the number of arriving migrants affects the social and economic indicators such as migration rate per 1,000 working-age people, remigration ratio, migration efficiency ratio, labor market strains, and migration impacts on the labor market. The municipalities of the Lipetsk region are differentiated according to the above-mentioned indicators describing the migration in the region. Such a differentiation identifies the groups characterized by a high or law impact of migration processes on the labor market. The development targets of the regional labor market are defined in view of factors affecting migration and providing market balance and its further development. The development targets are based on unified migration statistics, the improvement of social and economic environment, and the enhancement of laws and regulations in this regard.
Keywords: migration, labor migration, labor market, labor power, migration processes, correlation analysis, cluster analysis, development targets, Lipetsk region.

Миграция населения как одно из социально-экономических явлений оказывает существенное воздействие на развитие страны и отдельных ее регионов. Представляя собой перемещение населения из территории выезда в территорию въезда, миграция находится под воздействием следующих ключевых фракторов: демография, государственная политика, социально-экономические условия и законодательство. Наибольшее влияние на нее оказывают факторы двух групп: притягивающие и выталкивающие. Эти группы факторов действуют одновременно, но решающее значение имеют фракторы первой группы. В условиях, когда на первый план выходят фракторы второй группы, миграция приобретает вынужденный характер. Совокупность означенных факторов способствует как расширению миграционных процессов, так и их сужению.

Основной составляющей миграции населения выступает трудовая миграция, представляющая перемещение трудовых ресурсов, которые главным образом воздействуют на состояние и развитие рынка труда [1]. Их рациональное и сбалансированное распределение и использование обеспечивают рост производительности труда, эффективность деятельности предприятий и развитие экономики в целом. Следует отметить, что рынок труда характеризуется выраженной дифференциацией в разрезе субъектов Российской Федерации, что связано с масштабами территорий, региональной отраслевой спецификой, а также с различием в уровнях безработицы и социально-экономических условий [2].

Кроме этого, трудовая миграция оказывает влияние на социально-экономическое и научнотехническое развитие страны в связи с высокой экономической выгодой использования дешевой иностранной рабочей силы, что является негативным фактором для развития социально-эконо- 
мических условий для работников и использования результатов научно-технических исследований. Существующая несбалансированность на региональных рынках труда возникает вследствие несоответствия качественных характеристик спроса на трудовые ресурсы имеющемуся предложению. Складывается ситуация, когда одни регионы имеют переизбыток, а другие - недостаток трудовых ресурсов. Поэтому проблема регулирования трудовой миграции на региональном и федеральном уровнях и ее воздействие на рынок труда становятся актуальными в условиях существующего притока иностранных трудовых ресурсов.

Означенная проблема рассматривалась на примере Липецкой области, обладающей тенденциями роста по иммиграции, особенно трудоспособного возраста, а также широкопрофильностью видов экономической деятельности, осуществляемых в области. Исследуемый субъект характеризуется относительно высоким социально-экономическим рейтингом [3], что повышает уровень его привлекательности для прибывающих мигрантов. Все это вызывает необходимость определения влияния трудовой миграции на рынок труда Липецкой области для формирования целевых ориентиров его развития.

В целях определения наличия зависимости между трудовой миграцией и состоянием рынка труда проводился корреляционный анализ по основным показателям: коэффициент результативности миграционных связей (КРМС), коэффициент миграционной нагрузки на тысячу человек населения трудоспособного возраста (КМНТ), коэффициент миграционной нагрузки на рынок труда (КМНРТ), коэфффициент эффективности миграции (Эм) и коэфффициент напряженности на рынке труда (КНРТ) [4]. В результате проведенного корреляционного анализа установлено наличие сильной зависимости между количеством прибывающих мигрантов и показателями КРМС, КМНТ, Эм.

Таким образом, увеличение притока трудовой миграции в Липецкой области определяет рост нагрузки на тысячу человек населения трудоспособного возраста (0,94 по Пирсону) и величины миграционного прироста, приходящегося на одну заявленную потребность в работниках (0,49 по Пирсону). Обратная зависимость наблюдается по сокращению удельного веса миграционного прироста в миграционном обороте населения (-0,89 по Пирсону) и снижению напряженности на рынке труда (-0,56 по Пирсону)

В целях детализации влияния трудовой миграции на региональный рынок труда был проведен кластерный анализ, который позволил дифференцировать муниципальные образования Липецкой области по таким главным показателям, как количество прибывающих мигрантов (Пм), коэффициент интенсивности по прибытию в регион в трудоспособном возрасте (Кипт), коэффициент интенсивности по выбытию из региона (Кивм), коэффициент результативности миграционных связей (КРМС), эффективность миграции (Эм) и коэффициент миграционной компенсации в приросте (убыли) населения в трудоспособном возрасте (КМКт).

Результаты кластерного анализа для наглядности представлены в виде дендрограммы распределения муниципальных образований по классам, характеризующим влияние миграционных процессов на рынок труда (рисунок 1). Критериями оценки дифференцированных муниципальных образований Липецкой области выступают средние значения по каждому ключевому показателю.

Проведенная дифференциация муниципальных образований выделила три кластера, согласно которым в шести из двадцати районов Липецкой области миграционные процессы оказывают высокое влияние на состояние и развитие рынка труда. Следует отметить, что в большинстве районов влияние находится на среднем уровне и только в двух - на минимальном, где приток трудовой иммиграции незначителен (таблица 1).

\begin{tabular}{|c|c|c|c|c|c|c|c|c|}
\hline \multirow{2}{*}{ № кластера } & \multirow{2}{*}{ Состав кластера } & \multicolumn{6}{|c|}{ Средние значения } & \multirow{2}{*}{$\begin{array}{c}\text { Характеристика } \\
\text { кластера }\end{array}$} \\
\hline & & Пм & Кипт & Кивм & KPMC & Эм & КМКТ & \\
\hline $\begin{array}{l}1 \text { (6 муници- } \\
\text { пальных об- } \\
\text { разований) }\end{array}$ & $\begin{array}{l}\text { Города Липецк, Елец, } \\
\text { Грязинский, Задон- } \\
\text { ский, Липецкий, } \\
\text { Усманский районы }\end{array}$ & 622 & 8,1 & 6,1 & 260,9 & 60,1 & $-1,25$ & $\begin{array}{l}\text { Высокое влия- } \\
\text { ние миграцион- } \\
\text { ных процессов }\end{array}$ \\
\hline $\begin{array}{l}2 \text { (12 муни- } \\
\text { ципальных } \\
\text { образова- } \\
\text { ний) }\end{array}$ & $\begin{array}{l}\text { Воловский, Данков- } \\
\text { ский, Добринский, } \\
\text { Добровский, Долго- } \\
\text { руковский, Елецкий, } \\
\text { Измалковский, Лев- } \\
\text { Толстовский, Станов- } \\
\text { лянский, Тербунский, } \\
\text { Хлевенский, Чаплы- } \\
\text { гинский районы }\end{array}$ & 223,8 & 7,5 & 5,9 & 197,3 & 68,4 & 120,74 & $\begin{array}{l}\text { Среднее влия- } \\
\text { ние миграцион- } \\
\text { ных процессов }\end{array}$ \\
\hline $\begin{array}{l}3 \text { (2 муници- } \\
\text { пальных об- } \\
\text { разования) }\end{array}$ & $\begin{array}{l}\text { Краснинский, Лебе- } \\
\text { дянский районы }\end{array}$ & 123,5 & 3,1 & 0,1 & 910,5 & 5,3 & 120,01 & $\begin{array}{l}\text { Низкое влияние } \\
\text { миграционных } \\
\text { процессов }\end{array}$ \\
\hline
\end{tabular}




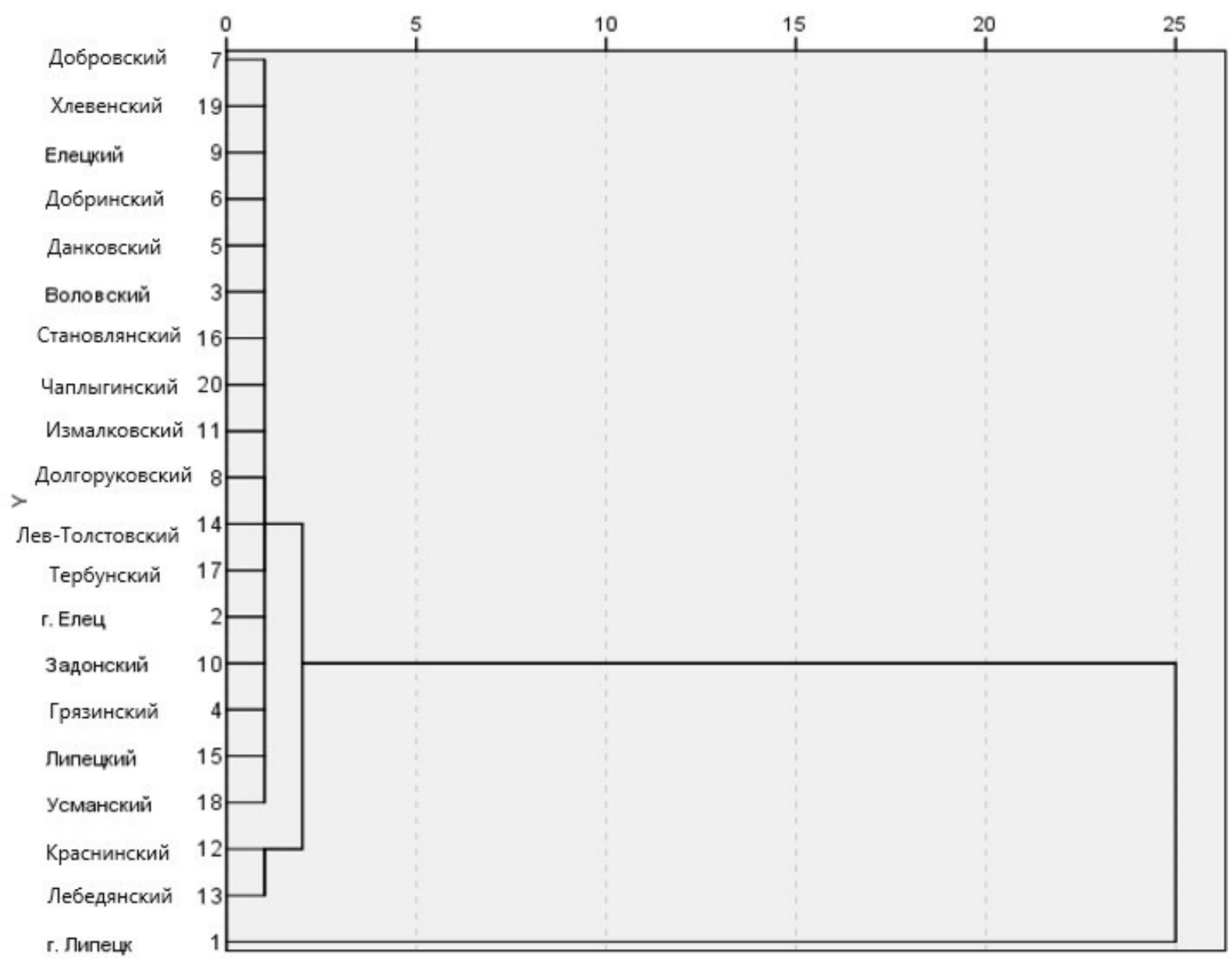

Рисунок 1 - Дендрограмма распределения муниципальных образований по классам [6]

Проведенное исследование показало, что Липецкая область характеризуется наличием зависимости рынка труда от иммиграции трудовых ресурсов в большинстве муниципальных образований региона, что вызывает необходимость регулирования рынка труда для его эффективного развития.

В целях устранения выявленных проблем определены целевые ориентиры развития регионального рынка труда с учетом факторов влияния на миграцию:

1. Унификация статистического учета - подразумевает единую методологию учета и информационную базу между всеми государственными органами, ответственными за учет прибывающих и находящихся на территории страны мигрантов, которая обеспечит более точный учет миграции населения, осуществляющих трудовую деятельность в России, что приведет к минимизации нелегальной трудовой иммиграции.

2. Повышение уровня социально-экономических условий труда - характеризуется реализацией государственных программ федерального и регионального уровня для стимулирования внутренней трудовой миграции как в отдельном регионе, так и в целом по стране, сокращая дисбаланс на рынке труда.

3. Совершенствование нормативно-правовой базы - предполагает установление на законодательной основе приоритета для коренного и русскоязычного иностранного населения при привлечении рабочей силы, что сократит долю нерусскоязычных мигрантов и минимизирует межэтническую напряженность в регионе и стране в целом.

4. Модернизация системы образования - подразумевает разработку новых федеральных государственных образовательных стандартов, отвечающих существующим потребностям в рабочей силе на рынке труда в целях минимизации дисбаланса между предложением и спросом на рабочую силу. На региональном уровне образовательные программы целесообразно акцентировать на технические и медицинские направленности специальностей.

5. Повышение занятости экономически неактивного населения - предполагает создание необходимых условий для продления трудовой деятельности путем стимулирования трудового потенциала работников предпенсионного и пенсионного возрастов, расширение процедур про- 
фессиональной переподготовки для повышения мобильности трудовых ресурсов в рыночно востребованные отрасли экономики, формирование условий для трудоустройства лиц с ограниченными ффизическими возможностями.

На основе кластерного анализа Липецкой области достижение рассмотренных ориентиров становится актуальным в районах с высоким влиянием миграционных процессов на рынок труда.

Данные целевые ориентиры, используемые на региональном уровне, будут способствовать минимизации формируемой потребности в иностранной рабочей силе, переориентированию ее на высококвалифицированных специалистов и сокращению потребностей регионов в трудовой иммиграции. Кроме этого, за счет стимулирования внутренней трудовой миграции повысится мобильность трудовых ресурсов, что в конечном итоге обеспечит сбалансированность и развитие российского рынка труда. Предложенные целевые ориентиры могут служить инструментами эфффективного функционирования рынков труда других регионов и страны в целом.

\section{Ссылки и примечания:}

1. Гневашева В.А. Миграционные процессы рынка труда // Современная наука: актуальные проблемы теории и практики. Серия: Экономика и право. 2017. № 5. С. 10-14; Юрков Д.В., Габдуллин Н.М. Развитие человеческого капитала территориального рынка труда на основе трудовой миграции // Вопросы экономики и права. 2016. № 11. С. 30-35 ; Dustmann Ch., Preston I. Estimating the Effect of Immigration on Wages [Электронный ресурс] : Norface Migration Discussion Paper No. 26. 2011. URL: http://www.norface-migration.org/publ_uploads/NDP_26_11.pdf (дата обращения: 10.04.2018) ; Solimano A. International Migration in the Age of Crisis and Globalization: Historical and Recent Experiences. N. Y., 2010. 240 p.

2. Васильева Е.В., Куклин А.А., Леонтьева А.Г. Социальная защита населения, ее роль в повышении качества жизни в регионах России // Уровень жизни населения регионов России. 2010. № 9. С. 22-31; Корнева Ж.В., Исмайлова Т.Ю. Развитие рынка труда в Липецкой области в период перехода к новому технологическому укладу // Регион: системы, экономика, управление. 2014. № 4 (27). С. 72-77 ; Коровкин А.Г., Единак Е.А., Шурпиков В.А. Анализ миграционной подвижности и приживаемости населения РФ // Научные труды: Институт народно-хозяйственного прогнозирования РАН. 2017. № 15. С. 442-446 ; Нехода Е.В., Соловьева Н.Н. Миграционные волны на российском рынке труда // Социологические исследования. 2016. № 4. С. 31-36.

3. Рейтинг социально-экономического положения субъектов РФ по итогам 2016 г. [Электронный ресурс] // РИА Рейтинг. 2017. 30 мая. URL: http://www.riarating.ru/infografika/20170530/630063754.html (дата обращения: 10.04.2018).

4. Миграция населения: теория и политика : учеб. пособие / под ред. О.Д. Воробьевой, А.В. Топилина и др. М., 2012. $364 \mathrm{c}$.

5. Таблица 1 рассчитана и составлена автором по данным Росстата. См.: Федеральная служба государственной статистики [Электронный ресурc]. URL: http://www.gks.ru (дата обращения: 10.04.2018).

6. Рисунок 1 составлен автором.

\section{References:}

Dustmann, Ch \& Preston, I 2011, Estimating the Effect of Immigration on Wages: Norface Migration Discussion Paper No. 26, viewed 10 April 2018, <http://www.norface-migration.org/publ_uploads/NDP_26_11.pdf>.

Gnevasheva, VA 2017, 'Migration processes of the labor market', Sovremennaya nauka: aktual'nyye problemy teorii i praktiki. Seriya: Ekonomika i pravo, No. 5, pp. 10-14, (in Russian).

Korneva, ZhV \& Ismaylova, TYu 2014, 'The labor market development in Lipetsk region during the transition to a new technological mode', Region: sistemy, ekonomika, upravleniy, No. 4 (27), pp. 72-77, (in Russian).

Korovkin, AG, Edinak, EA \& Shurpikov, VA 2017, 'Analysis of migration mobility and survival of the Russian Federation population', Nauchnyye trudy: Institut narodno-khozyaystvennogo prognozirovaniya RAN, No. 15, pp. 442-446, (in Russian).

Nekhoda, EV \& Solovyova, NN 2016, 'Migratory waves on the Russian labor market', Sotsiologicheskiye issledovaniya, No. 4, pp. 31-36, (in Russian).

Solimano, A 2010, International Migration in the Age of Crisis and Globalization: Historical and Recent Experiences, New York, $240 \mathrm{p}$

Vasilyeva, EV, Kuklin, AA \& Leontyeva, AG 2010, 'Social protection of the population, its role in improving the quality of life in the regions of Russia', Uroven' zhizni naseleniya regionov Rossii, No. 9, pp. 22-31, (in Russian).

Vorobyeva, OD \& Topilin, AV (et al.) (eds.) 2012, Population movement: theory and policy, manual, Moscow, 364 p., (in Russian).

Yurkov, DV \& Gabdullin, NM 2016, 'The development of the human capital of the territorial labor market on the basis of labor migration', Voprosy ekonomiki i prava, No. 11, pp. 30-35, (in Russian). 